\title{
Surgical management of postpartum hemorrhage
}

\author{
Number 4 - October 2020 \\ DOI: https://doi.org/10.1055/s-0040-1719159
}

The National Specialty Commission for Obstetric Emergencies of the Brazilian Federation of Gynecology and Obstetrics Associations (FEBRASGO) endorses to this document. The content production is based on scientific studies on a thematic proposal and the findings presented contribute to clinical practice.

\section{Key-points:}

- Postpartum hemorrhage is the world's leading cause of peripartum hysterectomy, even among women with a desire for future fertility.

- Vascular ligation and uterine compression sutures must precede hysterectomy in the surgical treatment of postpartum hemorrhage.

- The main technique of vascular ligation is bilateral uterine artery occlusion, although progressive devascularization techniques may optimize the surgical control of postpartum hemorrhage.

- Uterine compression sutures are heterogeneous and the choice of technique to be applied must correlate with the hemorrhage etiology and the topography of the hemorrhagic focus.

- The combination of uterine compression suture and vascular ligation increases the effectiveness of surgical treatment of postpartum hemorrhage.

- Surgical techniques for controlling postpartum hemorrhage should be used immediately after failure of drug therapy, preferably within the "golden hour".

- All pregnant women with placenta previa and previous cesarean section must have assisted birth in a tertiary service.

- Damage control surgery is indicated when the patient with postpartum hemorrhage is already in the lethal triad and definitive interruption of bleeding was not possible or requires excessive time.

\section{Recommendations:}

- In the surgical treatment of postpartum hemorrhage, when choosing vascular ligation and/or uterine compression sutures, the technique option must correlate with the topography of the hemorrhagic focus and the surgeon's skill and experience.

- If uterine atony occurs during cesarean section and drug therapy fails, uterine compression sutures of B-Lynch and Hayman and/or bilateral ligation of the ascending branches of the uterine arteries are excellent surgical options.

- In hemorrhage from placenta accreta that affects the uterine body, the Cho compression suture is an excellent surgical option. In placenta accreta of the uterine segment, both the Cho compression suture and low selective vascular ligations show excellent results in hemorrhagic control.

- If surgical techniques for uterine preservation fail, hysterectomy is indicated and should be performed as early as possible, before coagulopathy is installed. Unless there is concomitant infection or the hemorrhagic etiology is an invasive central placenta previa, subtotal hysterectomy should be preferred.

- The spectrum of placenta accreta in its previous increta and percreta varieties can be treated by means of hysterectomy or uteroplacental segmental excision followed by restoration of the uterine anatomy. Hysterotomy and fetal extraction should be performed outside the invaded uterine area, usually in the uterine fundus. Vascular neoformation must be carefully and selectively ligated and hysterectomy must be performed with the placenta in situ. In the face of bladder invasion by the placenta, partial cystectomy and/or reimplantation of the ureters may be necessary.

- In damage control surgery, the incisions must be large to facilitate technical execution. Open pelvic packing techniques with drainage reduce intestinal fistulas and increase the rate of primary closure. In patients undergoing total hysterectomy, damage control can be achieved through closed packing by adapting an intrauterine balloon in the pelvis.

- Skill training programs and simulations should be implemented in order to optimize the safety of care teams when applying surgical techniques to control postpartum hemorrhage. 


\section{Background}

Postpartum hemorrhage (PPH) is the world's leading cause of peripartum hysterectomy, even among women with a desire for future fertility. ${ }^{(1)}$ The main etiologies are uterine atony, birth canal trauma, ovarian tissue retention and coagulation disorders. Uterine atony is the etiology with the highest incidence and placenta accreta is the one with the highest lethality. The placenta accreta spectrum shows its higher incidence that correlates with the contemporary increase in cesarean section rates. Undoubtedly, the placenta percreta is the etiology of PPH that imposes greater surgical difficulty, especially when neighboring organs are affected.(2)

In recent decades, several techniques have been developed to preserve the uterus in PPH. Vascular ligation (VL), uterine compression suture (UCS), intrauterine balloons (IUBs), arterial embolization (AE) and intravascular balloons stand out. When well applied, surgical techniques (VL and UCS) can provide faster hemorrhagic control and potentially preserve fertility. ${ }^{(3)}$

\section{When and how to apply surgical techniques for uterine preservation?}

Vascular ligation and UCSs are surgical techniques for controlling PPH that provide uterine preservation, and may or may not be applied in combination. The main indication for these techniques is uterine atony with failure of drug therapy, especially during caesarean section. Other indications include placenta accreta, uterine inversion after repositioning the uterus and uterine rupture that can be preserved. These techniques stand out for their low cost, fast learning curves, high percentage of success in hemorrhagic control, fertility preservation, and for avoiding the additional loss of two or more liters of blood linked to hysterectomy. Therefore, they are indicated prior to hysterectomy. ${ }^{(4)}$

The chosen technique must correlate with the topography of the hemorrhagic focus, since the genital vascular region S1 (uterine fundus and body) is irrigated by the uterine and ovarian arteries, while region S2 (segment and cervix) receives blood supply from the internal pudendal, inferior vesical and middle, upper and lower vaginal arteries (Figure 1). Another important criterion when choosing the technique is the surgeon's skill, knowledge and experience with the techniques. ${ }^{(5)}$

The main $\mathrm{VL}$ technique is the bilateral uterine artery occlusion (O'Leary technique). Bilateral sutures are done in the ascending branches of the uterine arteries. Alternatively, "high" ligations can be added by using sutures in the utero-ovarian connections bilaterally located in the mesosalpinx. ${ }^{(6)}$ This technique is excellent for uterine atony of the genital vascular region S1, good for S1 accretism, but inefficient for hemorrhages in region S2. Very similar to the O'Leary technique, the Posadas technique consists of flexing the uterus

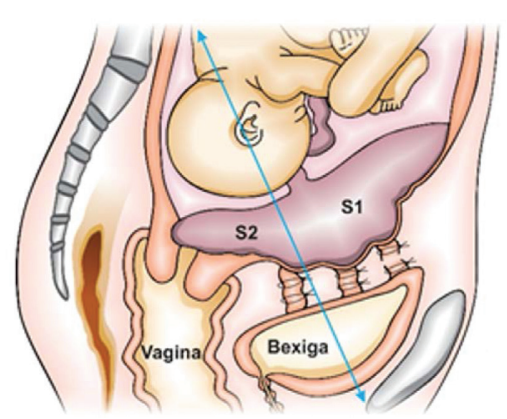

Source: Illustration by Felipe Lage Starling (authorized).

Figure 1. Sagittal scheme of the division of S1 and S2 genital vascular regions

towards the pubic bone, visualizing, palpating and ligating the ascending branches of the uterine arteries in their path in the posterior wall of the uterus. In addition, it is complemented by the occlusion of utero-ovarian connections in the mesosalpinx. ${ }^{(7)}$ In the triple ligation of Tsirulnikov, in addition to the sutures described above, sutures in the round ligament are added by obstructing the flow of the round ligament arteries. In step-by-step ligation techniques, sutures are progressively applied at 10-minute intervals. The hemorrhagic control after the application of a certain step is what determines the interruption in the application of sutures. In the AbdRabbo technique, the sutures are progressively applied to the ascending branches of the uterine arteries, to cervicouterine pedicles and to the ovarian arteries (infundibulopelvic ligaments). In the Morel technique, sutures are progressively applied to the ascending branches of the uterine arteries, round ligament arteries, utero-ovarian connections in the mesosalpinx and cervicouterine pedicles (Figure 2). ${ }^{(8)}$

In the presence of invasive placenta previa, low selective ligations applied in region S2 with the use of suture passer are the ideal techniques for hemorrhagic control from vascular neoformation associated with accretism. ${ }^{(5)}$ As the ligation of the internal iliac arteries (hypogastric) is performed far from the uterus and its annexes, it is less efficient than the other techniques when used alone. Its most accurate indications in $\mathrm{PPH}$ are severe lacerations of the birth canal and as a supporting procedure in the control of damage in patients already hysterectomized and in coagulopathy. ${ }^{(8,9)}$ In association with other uterine preservation techniques (IUB and UCS), this technique reduces hysterectomy rates. ${ }^{(10)}$

Uterine compression sutures provide mechanical compression in the uterine vascular sinus with simultaneous occlusion or not of the uterine arteries and other points of genital irrigation. The techniques are heterogeneous and what differentiates them is the figure in which the suture is applied, the number of 


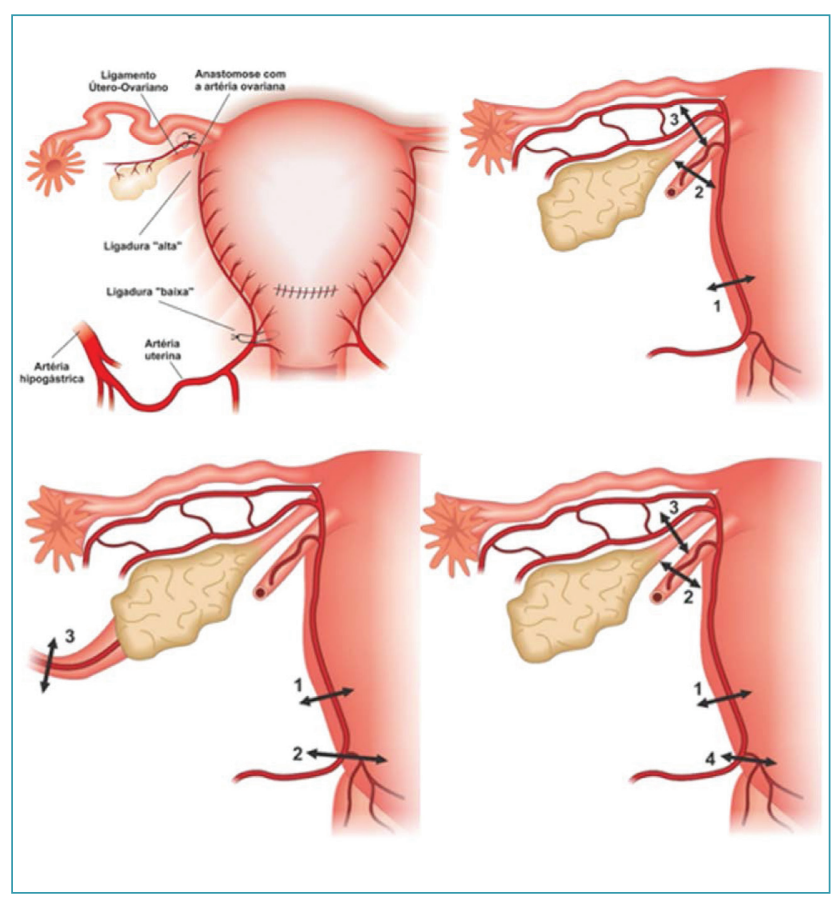

Source: Illustrations by Felipe Lage Starling (authorized).

Upper left: bilateral ligation of the ascending branches of uterine arteries and utero-ovarian connections in the mesosalpinx (O'Leary technique); upper right: Tsirulnikov's triple ligation (1 - ascending branch of the uterine artery; 2 - round ligament artery; 3 - utero-ovarian connections in the mesosalpinx); lower left: step-by-step AbdRabbo ligation (1 - ascending branch of the uterine artery; 2 - cervicouterine pedicle; 3 - ovarian artery); lower right: Morel step-by-step ligation (1 - ascending branch of the uterine artery; 2 round ligament artery; 3 - utero-ovarian connections in the mesosalpinx; 4 - cervicouterine pedicle).

Figure 2. Vascular ligation techniques

vertical and/or horizontal suture sets and the penetration/occlusion or not of the uterine cavity. To predict the success of the technique, the uterus must be compressed bimanually before the sutures are applied, while the vaginal blood loss is checked simultaneously. The main UCSs are those of B-Lynch, Cho and Hayman. The mechanism of action of the B-Lynch suture is the compression of the uterine fundus on the segment, simulating the effect of a uterine compression maneuver. The Cho suture promotes obliteration of the uterine cavity and can be selectively applied to hemorrhagic topographies. The Hayman's technique, on the other hand, has a mixed action mechanism, with compression of the uterine fundus on the segment, associated or not with the obliteration of the segmental uterine cavity. After exteriorization of the uterus, two loops are applied to the uterine segment in the anteroposterior direction, each at a 3-4 cm distance from the lateral border of the uterus, ending with the knots in the uterine fundus. ${ }^{(11)}$ Thus, the B-Lynch suture is excellent for uterine atony in the S1 region, good for accretion in $\mathrm{S} 1$ and ineffective for the $\mathrm{S} 2$ region. The Cho's technique is good for uterine atony in $\mathrm{S} 1$ and excellent for accretism both in $\mathrm{S} 1$ and S2. The Hayman suture is an excellent option for uterine atony in $\mathrm{S} 1$ and good for accretism both in $\mathrm{S} 1$ and S2 (Figure 3).

The effectiveness of UCSs increases when they are associated with VL. ${ }^{(12)} \mathrm{A}$ simple and efficient option is to associate bilateral ligation of the ascending branches of the uterine arteries with Hayman's upper vertical compressive loops. ${ }^{(13)}$ This strategy provides an association of techniques performed with only four needle passages in the uterus and is highly effective for the hemorrhagic control of uterine atony and accretism in the S1 region (Figure 4).

Another association that optimizes hemorrhagic control is the "uterine sandwich" technique, in which the UCS is associated with uterine balloon tamponade. In this situation, the balloon is inserted through the hysterotomy and the suture is applied under direct vision, preventing the needle from passing through the balloon. The balloon infusion should be limited to only $100 \mathrm{~mL}$ of saline and performed at the end of the surgery, after closing the UCS and laparorrhaphy. ${ }^{(14)}$

In order to prevent associated complications, the current trend is towards the development of removable UCSs. ${ }^{(15,16)}$ The main techniques already described are the Aboulfalah and Zhang USCs (removable B-Lynch and Hayman) (Figure 5).
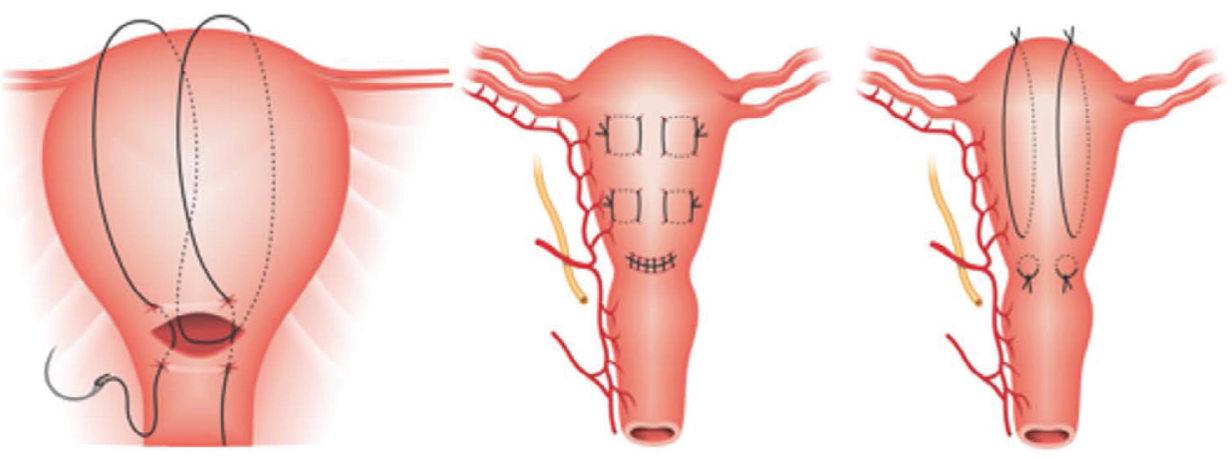

Source: Illustrations by Felipe Lage Starling (authorized).

Figure 3. B-Lynch, Cho and Hayman uterine compression sutures 


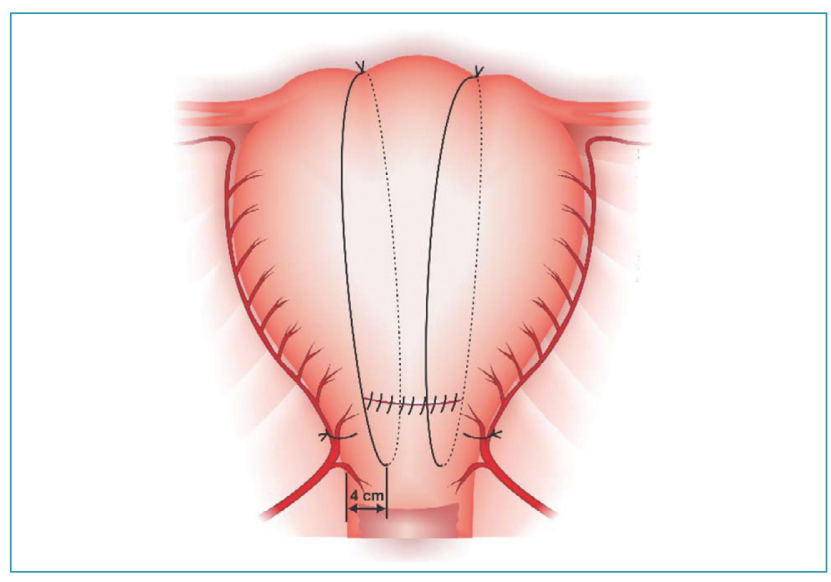

Source: Illustration by Felipe Lage Starling (authorized).

Ligation of the ascending branches of the uterine artery and vertical loops of the uterine compression suture

Figure 4. Technique of uterine devascularization and uterine compression suture

The main complications related to VL and UCSs are infections (pyometrium, endometritis and endomyometritis), ischemic partial necrosis, erosions, sulcus and defects in the uterine wall, synechiae, hematometrium, Asherman's syndrome and uterine rupture in subsequent pregnancy. ${ }^{(4)}$ Both VLs and UCSs must be made only with absorbable thread sutures. Polyglecaprone is the suture material of choice, with polyglactin and polydioxanone as second options. For the application of some techniques, straight needles may be necessary. ${ }^{(17)}$

\section{When and how to perform hysterectomy in uterine atony?}

Currently, hysterectomy should be the last stage of the surgical approach to PPH due to uterine atony and performed without delay before the installation of the lethal triad (coagulopathy, acidosis and hypothermia). Since the removal of the puerperal uterus imposes an additional loss of two to three liters of blood, its late performance can worsen the hemorrhagic shock. In the ab- sence of a central placenta previa or infection, subtotal hysterectomy should be preferred.(2)

\section{How to treat placenta accreta surgically?}

Every pregnant woman with placenta previa and prior cesarean section must have assisted birth in a tertiary service, because the treatment, especially of placenta percreta that invades neighboring organs (bladder, abdominal vessels), requires a multidisciplinary team. ${ }^{(18)}$

The surgical approach must be properly planned (reserve of blood components, definition of the anesthetic technique and laparotomy incision), performed by an experienced team and guided according to the invaded genital vascular region (S1 or S2). Since placental blood flow at gestational term is 600 to $700 \mathrm{~mL} / \mathrm{min}$, elective interruption between 35 and 38 weeks is consensus. ${ }^{(5,19)}$

Starting with spinal anesthesia until fetal extraction, then proceeding to general anesthesia is a good strategy in the face of prolonged surgical time often imposed by the need for extensive dissection of vascular neoformations. After wide laparotomy (longitudinal incisions may be necessary) and adequate uterine exposure, hysterotomy and fetal extraction should be performed outside the invaded uterine area. Thus, fundal hysterotomies should be preferred. After clamping and removal of the umbilical cord, hysterorrhaphy is performed with the placenta in situ. The ureters and internal iliac arteries (hypogastric) should be located and the surgical technique defined. The exeresis by segmental excision followed by restoration of the uterine anatomy may be preferable to hysterectomy. Both require experience and dexterity from the surgeon to perform the low selective ligation (using suture passer) of vascular neoformations, especially in the uterine segment. In hysterectomy performed by means of high vascularization and uterovesical adhesion, mobilization and bladder dissection (Pelosi by-pass) performed in zones of adhesion are useful in preventing urinary tract injuries (Figures 6, 7, 8 and 9). In the face of bladder invasion by the placenta, one of

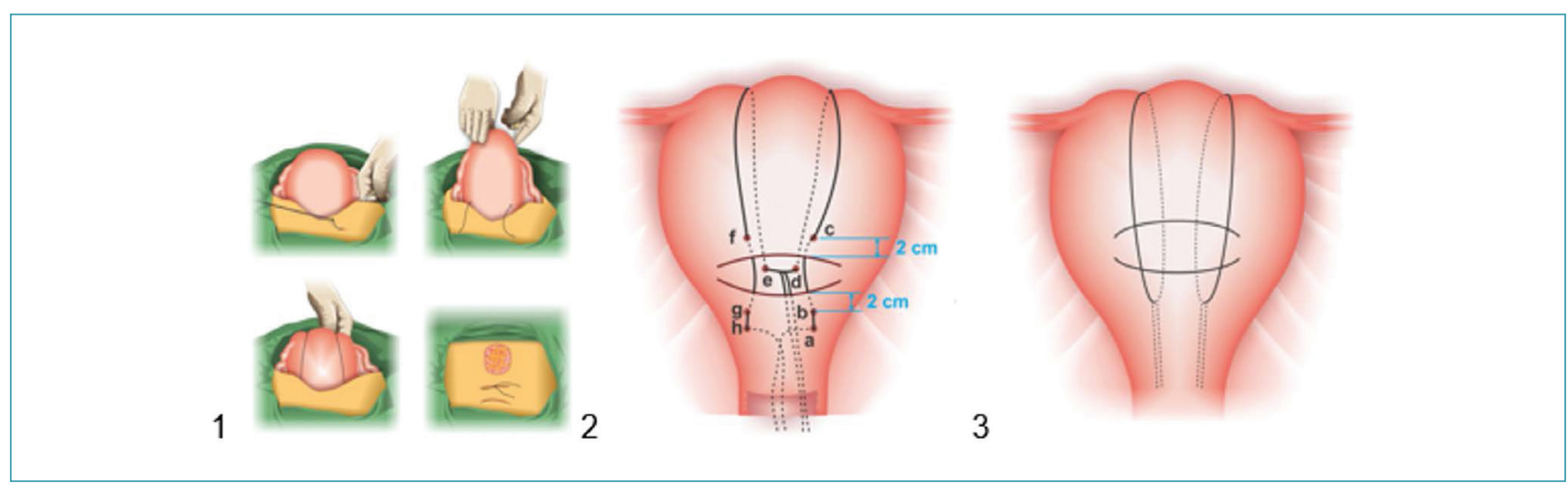

Source: Illustrations by Felipe Lage Starling (authorized).

1 - Aboulfalah; 2 - Removable B-Lynch by Zhang; 3 - Removable Hayman by Zhang.

Figure 5. Removable uterine compression sutures 


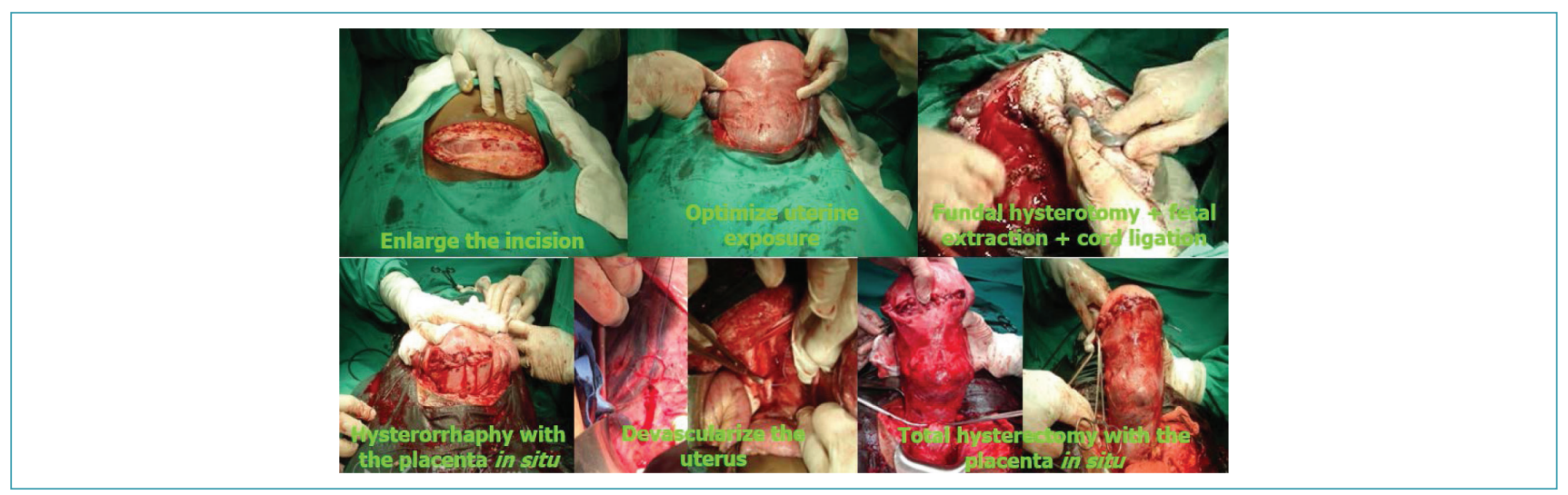

Figure 6. Steps of the cesarean-hysterectomy technique in the surgical treatment of placenta accreta

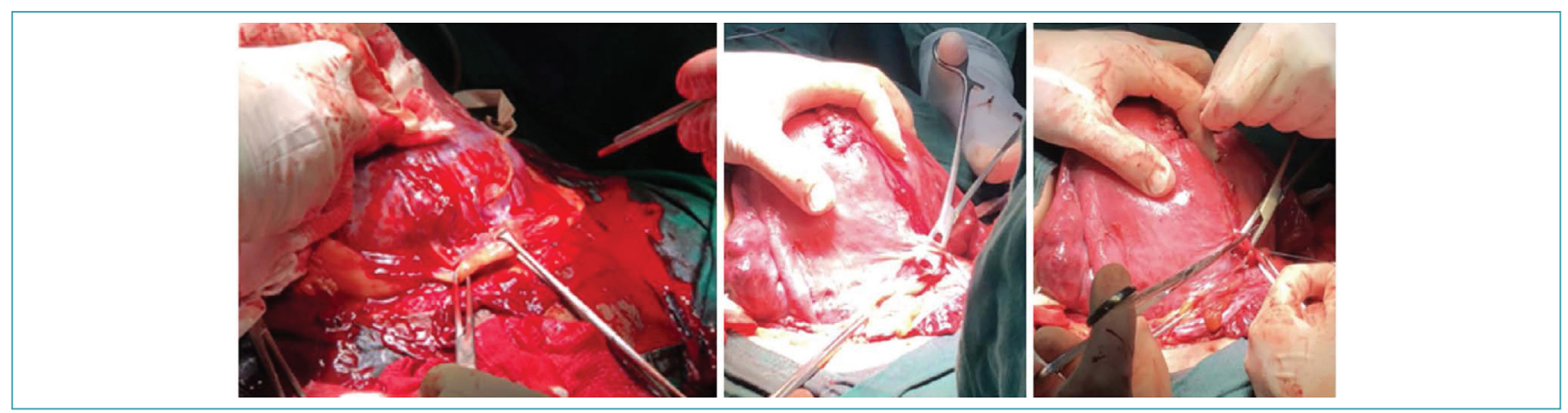

Exposure of vascular neoformations present in vesicouterine reflection by means of traction with Allis forceps. Double ligation performed with a suture passer.

Figure 7. Low selective ligation of vascular neoformations present in the uterine segment in the surgical treatment of placenta accreta
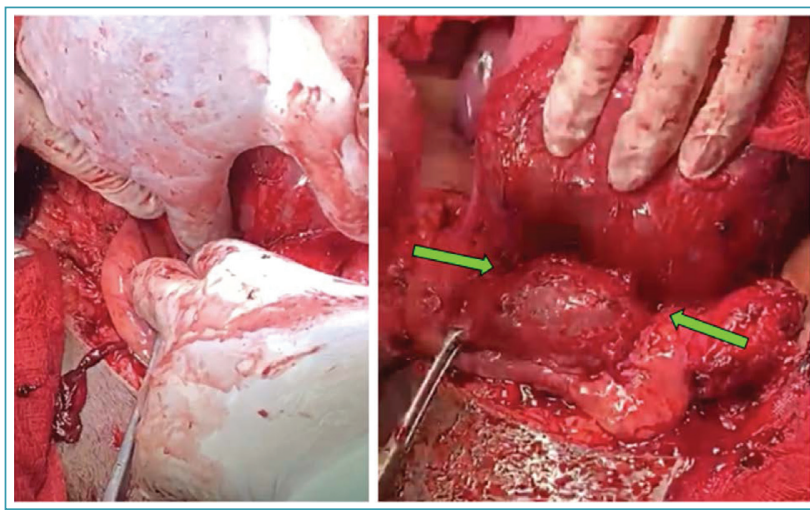

After performing the low selective ligation of vascular neoformations, mobilization and blunt dissection of the vesicouterine space are performed.

Figure 8. Mobilization and bladder dissection (Pelosi by-pass) performed in the areas of vesicouterine adhesions in the surgical treatment of placenta accreta

the options is to perform partial cystectomy and "onepiece" hysterectomy (Pelosi technique). ${ }^{(20)}$ As an alternative to partial cystectomy, and especially in the face of invasion of the bladder trigone (rare), embolization of the uterine and internal pudendal arteries is a good option for sites with this technical availability. Eventually, ureteral reimplantation is necessary. An alternative for the control of hemorrhage in the genital vascular region S2

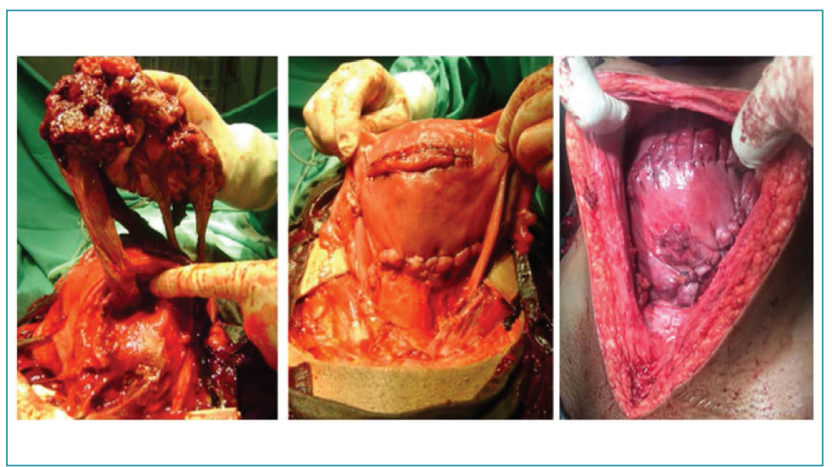

Left: exeresis of the uterine segment affected by invasion of placental cotyledons and ovular membranes. Center and right: final result of restoration of the uterine anatomy with hysterorrhaphy in the uterine fundus and suture between the uterine body and the lower residual portion of the segment.

Figure 9. Exeresis with segmental uteroplacental excision followed by restoration of uterine anatomy in the surgical treatment of placenta accreta

is the application of segmental UCSs. The most suitable techniques for this purpose are the Cho UCSs (adapted by Palacios-Jaraquemada), ${ }^{(5,19)}$ Dedes and Zioga or the transverse segmental figure-of-8 UCS (Figure 10). The strategies described above offer the advantage of onestep surgical resolution.

In exceptional situations, such as in extrauterine placental implantations (in large vessels or adjacent 

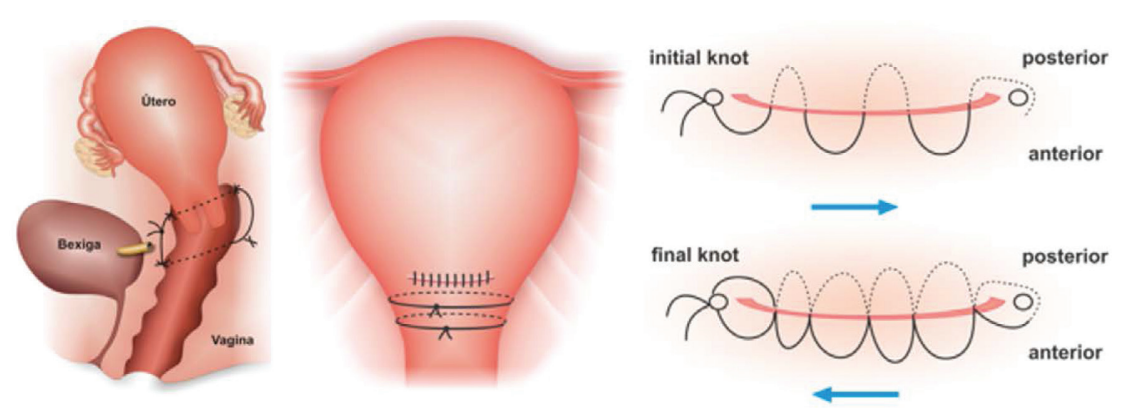

Figure 10. Cho uterine compression sutures (adapted by Palacios-Jaraquemada), ${ }^{(19)}$ Dedes and Zioga and transverse segmental figure-of- 8

organs), maintaining the placenta in situ associated or not with methotrexate or arterial embolization may be the safest resource. ${ }^{(19)}$

In the face of prenatal diagnostic failure followed by perioperative diagnosis in non-ideal surgical conditions (lack of experience of the team and/or blood components), the surgical procedure must be restricted to hysterotomy and fetal extraction outside the invaded uterine area, followed by hysterorrhaphy with the placenta in situ and laparorraphy. In these situations, the definitive re-approach (hysterectomy or excision with uteroplacental segmental exeresis followed by restoration of the uterine anatomy) is performed after the reorganization of the care conditions (two step). ${ }^{(5,19)}$

\section{When and how to perform damage control surgery?}

Damage control surgery (pelvic packing and laparostomy, with or without concomitant ligation of the internal iliac arteries) is indicated when definitive bleeding control was not possible or when it demands excessive time and the patient is already in the lethal triad. The goal is to temporarily control the hemorrhagic focus and allow the restoration of the patient's physiology in intensive care. The surgery is temporary. The control of the remaining hemorrhagic foci and the permanent laparorrhaphy should be performed two to five days later.(20,21)

Open pelvic packing techniques with drainage reduce intestinal fistulas and increase the rate of primary closure. Longitudinal incisions may be necessary for good technical execution. A good option for open packing (laparorrhaphy) includes the insertion of 7 to 10 compresses in the pelvis and a fenestrated pouch above the package that will not be sutured, being loose and below the parietal peritoneum. Above this first bag, two compresses are allocated. Above these, one or two drains, plus two compresses for top drain protection are placed. The technique is completed with the insertion of a second, non-fenestrated pouch sutured directly to the skin. As alternative to this second pouch, an adherent dressing involving the entire abdominal circumference can be applied. The drains must be adapted to the suction system at a negative pressure between -100 and $-150 \mathrm{mmHg} .^{(22,23)}$

In patients undergoing total hysterectomy, damage control can be achieved through closed packing. In this technique, an intrauterine balloon is inserted into the pelvis and its axis is directed to the vaginal cavity, before the approach to the vaginal dome. After laparorraphy and the balloon infusion, a weight is connected to its axis and adapted to the bedside in order to optimize pelvic compression (Figure 11). In this technical option, surgical re-approach is not necessary. After physiological restoration, the balloon is deflated and removed through the vagina. ${ }^{(24,25)}$

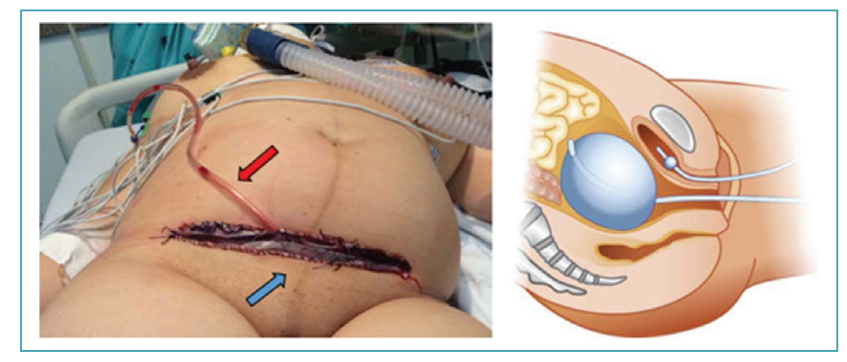

Left: open pelvic packing; the red arrow indicates aspiration; the blue arrow indicates the protective pouch of the pelvic pack made with compresses. Right: closed packing with an intrauterine balloon adapted to the pelvis.

Figure 11. Pelvic packing damage control surgery

Still in the context of care to puerperal women in critical situation due to severe PPH, such as imminent cardiopulmonary arrest and extra-hospital care, the external manual compression of the infrarenal aorta can be performed as a life-saving maneuver. Compression should be temporary (maximum 90 minutes) with the application of a force of approximately $45 \mathrm{~kg}$ and performed until the arrival of support and/or the start of correction of coagulopathy and shock. ${ }^{(26)}$

Finally, the evolution of the HPP assistance flowcharts with incorporation of several more recent surgical idealization and evaluation techniques imposed on care teams the need to acquire new skills and competences. These can be obtained through skills training programs and simulations aimed at optimizing the safety and technical quality of the care teams. ${ }^{(27)}$ 


\section{Final considerations}

Since HPP is the major cause of maternal mortality worldwide, health care teams' ability to institute surgical treatment, preferably within the "golden hour", becomes essential in the event of drug treatment failure. The contemporary development of invasive techniques that preserve the uterus and have high rates of success in hemorrhagic control has changed the sequencing of surgical treatment for PPH. These techniques, including IUB, UCS, VL, AE and their associations must precede hysterectomy and their choice must correlate with the mode of delivery, PPH etiology, topography of the hemorrhagic focus and valuably, with the skill and experience of professionals. However, in view of the failure of surgical techniques that preserve the uterus, hysterectomy should be performed as early as possible, before the installation of coagulopathy. Hysterectomy is also frequently required as a primary treatment in the face of the spectrum of placenta accreta, especially in increta and percreta varieties associated with unfavorable conditions for uteroplacental segmental exeresis and restoration of uterine anatomy. In these situations, the complexity of the operative tactic and severity of the risks demand adequate surgical conditions and a qualified and experienced multidisciplinary team. Since it is a cause of high lethality, high incidence and complex and specialized surgical treatment, its current impact on the planning and reorganization of care teams is significant.

\section{References}

1. Bodelon C, Bernabe-Ortiz A, Schiff MA, Reed SD. Factors associated with peripartum hysterectomy. Obstet Gynecol. 2009;114(1):115-23. doi: 10.1097| AOG.0b013e3181a81cdd

2. American College of Obstetricians and Gynecologists. Committee on Practice Bulletins-Obstetrics. Practice Bulletin No 183: postpartum hemorrhage. Obstet Gynecol. 2017;130(4):e168-86. doi: 10.1097|AOG.0000000000002351

3. Chandraharan E, Arulkumaran S. Surgical aspects of postpartum haemorrhage. Best Pract Res Clin Obstet Gynaecol. 2008;22(6):1089-102. doi: 10.1016/j.bpobgyn.2008.08.001

4. Doumouchtsis SK, Papageorghiou AT, Arulkumaran S. Systematic review of conservative management of postpartum haemorrhage: what to do when medical treatment fails. Obstet Gynecol Surv. 2007;62(8):540-7. doi: 10.1097/01. ogx.0000271137.81361.93

5. Palacios-Jaraquemada JM. Surgical anatomy. In: PalaciosJaraquemada JM. Placental adhesive disorders. Berlin: De Gruyter; 2012. p. 43-78.

6. Moise $\mathrm{KJ} \mathrm{Jr}$, Belfort MA. Damage control for the obstetric patient. Surg Clin North Am. 1997;77(4):835-52. doi: 10.1016| s0039-6109(05)70588-0

7. Posadas-Nava A, Moreno-Santillán AA, Celis-González C, Cruz-Martínez E. Control efectivo de la hemorragia obstétrica posparto mediante desarterialización selectiva uterina. Descripción de la técnica Posadas. Ginecol Obstet Mex. 2016;84(12):808-13.
8. Morel O, Malartic C, Muhlstein J, Gayat E, Judlin P, Soyer P, et al. Pelvic arterial ligations for severe post-partum hemorraghe. Indications and techniques. J Visc Surg. 2011;148(2):e95-102. doi: 10.1016/j.jviscsurg.2011.02.002

9. Sziller I, Hupuczi P, Papp Z. Hypogastric artery ligation for severe hemorrhage in obstetric patients. J Perinat Med. 2007;35(3):187-92. doi: 10.1515/JPM.2007.049

10. Kaya B, Damarer Z, Daglar K, Unal O, Soliman A, Guralp O. Is there yet a role for internal iliac artery ligation in obstetric hemorrhage with the current gain in popularity of other uterus sparing techniques? J Matern Fetal Neonatal Med. 2017;30(11):1325-32. doi: 10.1080/14767058.2016.1212333

11. Palacios-Jaraquemada JM. Efficacy of surgical techniques to control obstetric hemorrhage: analysis of 539 cases. Acta Obstet Gynecol Scand. 2011;90(9):1036-42. doi: 10.1111/j.1600-0412.2011.01176.x

12. Kaya B, Tuten A, Daglar K, Onkun M, Sucu S, Dogan A, et al. B-Lynch uterine compression sutures in the conservative surgical management of uterine atony. Arch Gynecol Obstet. 2015;291(5):1005-14. doi: 10.1007/s00404-014-3511-2

13. Alves ALL, Senra JC, São José CN, Ribeiro BR, Furtado RS, Silva LB, et al. Uterine desvascularization associated with compressive uterine suture (UD-CUS) in surgical treatment of postpartum hemorrhage. Int J Gynecol Obstet. 2020;149(1):111-2. doi: 10.1002/ijgo.13081

14. Yoong W, Ridout A, Memtsa M, Stavroulis A, Aref-Adib M, Ramsay-Marcelle Z, et al. Application of uterine compression suture in association with intrauterine balloon tamponade ('uterine sandwich') for postpartum hemorrhage. Acta Obstet Gynecol Scand. 2012;91(1):147-51. doi: 10.1111/j.16000412.2011.01153.x

15. Aboulfalah A, Fakhir B, Kaddour YAB, Asmouki H, Soummani A. $A$ new removable uterine compression by a brace suture in the management of severe postpartum hemorrhage. Front Surg. 2014;1:43. doi: 10.3389/fsurg.2014.00043

16. Zhang ZW, Liu CY, Yu N, Guo W. Removable uterine compression sutures for postpartum haemorrhage. BJOG. 2015;122(3):42933. doi: $10.1111 / 1471-0528.13025$

17. Mallappa Saroja CS, Nankani A, El-Hamamy E. Uterine compression sutures, an update: review of efficacy, safety and complications of B-Lynch suture and other uterine compression techniques for postpartum haemorrhage. Arch Gynecol Obstet. 2010;281(4):581-8. doi: 10.1007/s00404-009-1249-z

18. Clark SL, Hankins GDV. Preventing maternal death: 10 clinical diamonds. Obstet Gynecol. 2012;119(2 Pt 1):360-4. doi: 10.1097/AOG.0b013e3182411907

19. Palacios-Jaraquemada JM. Caesarean section in cases of placenta praevia and accreta. Best Pract Res Clin Obstet Gynaecol. 2013;27(2):221-32. doi: 10.1016/j.bpobgyn.2012.10.003

20. Pelosi MA 3rd, Pelosi MA. Modified cesarean hysterectomy for placenta previa percreta with bladder invasion: retrovesical lower uterine segment bypass. Obstet Gynecol. 1999;93(5 Pt 2):830-3. doi: 10.1016/s0029-7844(98)00426-8

21. Carvajal JA, Ramos I, Kusanovic JP, Escobar MF. Damage-control resuscitation in obstetrics. J Matern Fetal Neonatal Med. 2020 Feb 26. doi: 10.1080/14767058.2020.1730800. [ahead of print]

22. Barker DE, Kaufman HJ, Smith LA, Ciraulo DL, Richart CL, Burns RP. Vacuum pack technique of temporary abdominal closure: a 7-year experience with 112 patients. J Trauma. 2000;48(2):2017. doi: 10.1097/00005373-200002000-00001

23. Rezende-Neto JB, Cunha-Melo JR, Andrade MV. Cobertura temporária da cavidade abdominal com curativo a vácuo. Rev Col Bras Cir. 2007;34(5):336-9. doi: 10.1590/S010069912007000500011 
24. Waks A, Tabsh K, Tabsh K, Afshar Y. Balloon uterine tamponade device after peripartum histerectomy for morbidly adherent placenta. Obstet Gynecol. 2018;132(3):643-6. doi: 10.1097| AOG. 0000000000002792

25. Charoenkwan K. Effective use of the Bakri postpartum balloon for posthysterectomy pelvic floor hemorrhage. Am J Obstet Gynecol. 2014;210(6):586.e1-e3. doi: 10.1016/j. ajog.2014.03.068

26. Soltan MH, Faragallah MF, Mosabah MH, Al-Adawy AR. External aortic compression device: the first aid for postpartum hemorrhage control. J Obstet Gynaecol Res. 2009;35(3):453-8. doi: 10.1111/j.1447-0756.2008.00975.x

27. Ghaem-Maghami S, Brockbank E, Bridges J. Survey of surgical experience during training in obstetrics and gynaecology in the UK. J Obstet Gynaecol. 2006;26(4):297-301. doi: $10.1080 / 01443610600594740$
Álvaro Luiz Lage Alves ${ }^{1}$

'Faculdade Ciências Médicas de Minas Gerais, Belo Horizonte, MG, Brazil.

Gilberto Nagahama²

${ }^{2}$ Maternidade Escola Vila Nova Cachoeirinha, São Paulo, SP, Brazil.

Alexandre Massao Nozaki ${ }^{3}$

${ }^{3}$ Hospital Maternidade Interlagos, São Paulo, SP, Brazil.

Conflict of interest: none to declare.

National Specialty Commission for Obstetric Emergencies of the Brazilian Federation of Gynecology and Obstetrics Associations (FEBRASGO)

President:

Álvaro Luiz Lage Alves

Members:

Gabriel Costa Osanan

Samira El Maerrawi Tebecherane Haddad

Adriana Amorim Francisco

Alexandre Massao Nozaki

Brena Carvalho Pinto de Melo

Breno José Acauan Filho

Carla Betina Andreucci Polido

Eduardo Cordioli

Frederico José Amedée Peret

Gilberto Nagahama

Laíses Braga Vieira

Lucas Barbosa da Silva

Marcelo Guimarães Rodrigues

Rodrigo Dias Nunes

Roxana Knobel 